\title{
Influence of sex steroids on the viability and CD11b, CD18 and CD47 expression of blood neutrophils from dairy cows in the last month of gestation
}

\author{
Inge LAmote, Evelyne MeYer, Adelheid De KetElaere, \\ Luc DuCHATEAU, Christian BURVENICH* \\ Department of Physiology, Biochemistry and Biometrics, Faculty of Veterinary Medicine, \\ Ghent University, Salisburylaan 133, 9820 Merelbeke, Belgium
}

(Received 23 December 2004; accepted 20 June 2005)

\begin{abstract}
In the period around parturition, cows experience an increased susceptibility for the development of Escherichia coli mastitis. This increased susceptibility has been correlated with a decreased functionality of neutrophils. In the current study, it is suggested that the decreased neutrophil functionality may be induced by the extensive alterations in sex steroid levels occurring around parturition. It was first hypothesized that $17 \beta$-estradiol and progesterone influence the viability, apoptosis and necrosis of blood neutrophils from cows in their last month of gestation. Subsequently, it was hypothesized that $17 \beta$-estradiol modulates the expression of CD11b, CD18 or CD47 thereby explaining its influence on the migration of bovine neutrophils. Neither 17 $\beta$-estradiol nor progesterone significantly influenced viability, apoptosis or necrosis in spontaneous apoptosis conditions. However, when apoptosis was induced with TNF- $\alpha$ and gliotoxin, progesterone exerted a survival effect $(P<0.05)$. In addition, $17 \beta$-estradiol treatment of bovine blood neutrophils significantly decreased the expression of CD47 $(P<0.05)$ but not of CD11b or CD18. It can be concluded that $17 \beta$-estradiol and progesterone do not affect spontaneous apoptosis of bovine blood neutrophils while a survival effect was observed for progesterone on induced neutrophils apoptosis. Moreover, our results concerning the influence of $17 \beta$-estradiol on the CD11b, CD18 and CD47 expression extend previous demonstrations of the suppressive effect of $17 \beta$-estradiol on neutrophils migration and indicate that the altered expression of CD47 may contribute to this phenomenon.
\end{abstract}

sex steroid / $\beta_{2}$-integrin / CD47 / viability / polymorphonuclear neutrophil leukocyte

\section{INTRODUCTION}

The susceptibility of dairy cows to infectious diseases is significantly increased around parturition and during early lactation. Severe clinical Escherichia coli (E. coli) mastitis with systemic symptoms typically occurs in these periods whereas during established lactation, coliform mastitis is a moderate and self-curing disease. It is well recognized that this increased incidence is related to a decreased function of the immune system [3]. Among the immune cells affected in the period around parturition, polymorphonuclear neutrophil leukocytes (PMN) have been of particular interest since they play an important role in the defense against E. coli. Several reports

* Corresponding author: Christian.Burvenich@ugent.be 
concerning the functional capacity of PMN during the periparturient period have been described (reviewed by Diez-Fraile et al. [8]). Despite some conflicting results, it can generally be concluded from these studies that almost all important PMN functions are compromised at some time during the periparturient period. Although the exact causes for a compromised PMN function are not fully understood, they are believed to be at least influenced by the hormonal changes associated with pregnancy, parturition, and the onset of lactation.

Parturition and the onset of lactation comprise extensive alterations in sex steroid levels. 17 $\beta$-estradiol levels rise steeply in the last week before parturition, peak in the last three days before delivery, fall rapidly after calving and regain basal values. The high concentration of progesterone, associated with pregnancy, declines at the end of gestation and a dramatic fall occurs in the last two days before delivery $[1,2$, 23 ]. It is suggested that the extensive alterations in $17 \beta$-estradiol and progesterone levels might be responsible for the induction of a compromised immune response around parturition.

In view of this hypothesis, the effect of sex steroid hormones has previously been determined for some PMN functions [13, 29, 33]. The exact influence of sex steroids is, however, still incompletely understood. Indeed, their effect on viability, apoptosis and necrosis and on the CD11b, CD18 and CD47 expression of PMN is only poorly documented and reports are limited to human PMN [7, 11, 17, 22].

A positive influence of endogenous sex steroid levels on the viability of human PMN has been suggested since a delay in spontaneous apoptosis is observed in women of reproductive age compared with agematched men [22]. Moreover, apoptosis of PMN from women at the end of pregnancy is extensively delayed [37]. Evaluation of the administration of $17 \beta$-estradiol and/or progesterone to human PMN confirmed this suggestion. Physiological doses of
$17 \beta$-estradiol and progesterone caused a delay in spontaneous apoptosis [22].

In addition to their direct influence on the viability of human PMN, sex steroid hormones can also indirectly act as survival factors. It has been described for $17 \beta$-estradiol and progesterone that they can reverse apoptosis of monoblastoid cells induced by pro-apoptotic modulators such as TNF- $\alpha$ [36]. Evidence for a role of steroids as survival factors in bovine PMN is scarce and limited to glucocorticosteroids [5, 19]. Moreover, whereas TNF- $\alpha$ can induce apoptosis of human PMN, it is difficult to reproduce this effect for bovine PMN. However, in combination with the NF- $\kappa B$ inhibitor gliotoxin, the limited pro-apoptotic effect of TNF- $\alpha$ can dramatically be augmented [25].

Apart from viability and apoptosis, PMN migration is another important parameter in the outcome of mastitis. Upon infection, PMN need to migrate efficiently from the blood towards the mammary gland. PMN migration is an essential component of the dynamic (inflammatory) phase of the innate immune defense. Apart from the PMN influx from blood, the number and function of PMN that pre-exist in the mammary gland before infection is also correlated with the outcome of mastitis. These resident milk PMN, i.e. PMN not stimulated by inflammatory mediators, represent the static phase of the innate immune defense and are responsible for a fast response of the immune system against invading pathogens $[3,4,15]$.

In order to reach the mammary gland, circulating PMN have to attach to the endothelium and migrate (diapedesis) from the blood through the endothelium, extracellular matrix and mammary epithelium to the site of infection following a chemoattractant gradient. Adhesion molecules are involved in this process. Among the latter, the $\beta_{2}$-integrin subunits CD11b and CD18 are of critical importance for migration of bovine PMN through collagen and epithelial cells [32]. Additionally, an integrin associated protein termed CD47 has more 
recently been shown to play an important role in the migration of human PMN through intestinal epithelial cells and collagen [18]. The presence and the importance of CD47 for migration has, however, not yet been reported for bovine PMN.

Concerning the influence of $17 \beta$-estradiol and progesterone on PMN migration, studies agree for $17 \beta$-estradiol but not for progesterone. Indeed, studies report a negative influence of $17 \beta$-estradiol on the migration of human $[14,21]$ and bovine PMN [16] whereas the influence of progesterone is less clear. In order to gain insight into the suppressive effect of $17 \beta$-estradiol on PMN migration, its influence on the expression of CD11b, CD18 and CD47 should be evaluated.

In this study it is first hypothesized that $17 \beta$-estradiol and progesterone influence PMN viability, apoptosis and necrosis. It is suggested that these sex steroids can exert their influence either on spontaneous apoptosis or that they will delay apoptosis and necrosis induced by TNF- $\alpha$ and gliotoxin.

Subsequently, it is hypothesized that $17 \beta$-estradiol influences CD11b, CD18 and CD47 expression, thereby explaining the influence of $17 \beta$-estradiol on PMN migration. Before this analysis was performed, the surface expression of CD47 was determined and the importance of CD47 for migration of bovine PMN was assessed.

\section{MATERIALS AND METHODS}

\subsection{Animals and blood sample collection}

Clinically healthy Holstein cows in their last month of gestation ( 8 to 30 days before parturition) were selected. Five cows were used to study the influence of $17 \beta$-estradiol and progesterone on the viability, apoptosis and necrosis of PMN and six other cows were used for the assessment of the effect of $17 \beta$-estradiol and progesterone on TNF- $\alpha$ and gliotoxin induced apoptosis and necrosis (experiment 1). Seven cows were used to evaluate the importance of CD47 for PMN migration (experiment 2). Finally, seven cows were used to determine the influence of $17 \beta$-estradiol on the expression of CD11b, CD18 and CD47 (experiment 3 ). Blood was collected via venipuncture of the jugular vein using $60-\mathrm{mL}$ sterile tubes containing $30 \mathrm{~mL}$ Alsever solution as an anticoagulant.

\subsection{Isolation of PMN}

PMN were isolated using a method described by Roets et al. [28]. Briefly, after removal of the plasma and buffy coat, erythrocytes were lysed with $\mathrm{NH}_{4} \mathrm{Cl}$ and the cell pellet was washed twice. The cell pellets comprising isolated PMN were then resuspended and the cell concentration of the suspension was determined using a Coulter counter (Coulter counter ZF, Coulter electronics Ltd, Luton, UK). The purity of the PMN isolates was determined light microscopically by differentiation. At least $85 \%$ of the isolated cells were PMN. Contaminating cells were mainly eosinophils and to a lesser extent lymphocytes.

\subsection{Incubation of PMN with $17 \beta$-estradiol, progesterone, TNF- $\alpha$ and gliotoxin}

In a first experiment, PMN were incubated with $0.01,1$ and $10 \mathrm{ng} / \mathrm{mL} 17 \beta$-estradiol (1,3,5(10)-Estratriene-3,17 $\beta$-diol) or with 5,50 and $500 \mathrm{ng} / \mathrm{mL}$ progesterone (4-Pregnene-3,20-dione) during $24 \mathrm{~h}$ at $37{ }^{\circ} \mathrm{C}$ (experiment 1). The influence of $17 \beta$-estradiol and progesterone on the viability, apoptosis and necrosis was assessed after 1, 3, 6 and $24 \mathrm{~h}$ of incubation. In order to evaluate the influence of $17 \beta$-estradiol and progesterone on the TNF- $\alpha$ and gliotoxin induced apoptosis and necrosis (experiment 1), PMN were simultaneously incubated with $0.1 \mu \mathrm{g} / \mathrm{mL}$ gliotoxin (Sigma Chemicals Co., St. Louis, USA), $10 \mathrm{ng} / \mathrm{mL}$ recombinant bovine TNF- $\alpha$ (Endogen, Pierce Biotechnology, Rockford, IL, USA) and $1 \mathrm{ng} / \mathrm{mL} 17 \beta$-estradiol or $50 \mathrm{ng} / \mathrm{mL}$ progesterone. The influence of $17 \beta$-estradiol and 
progesterone on the TNF- $\alpha$ and gliotoxin induced apoptosis and necrosis was assessed after 1,3 and $5 \mathrm{~h}$ of incubation. For the evaluation of the influence of $17 \beta$-estradiol on the CD11b, CD18 and CD47 expression (experiment 3 ), PMN were incubated with $1 \mathrm{ng} / \mathrm{mL} 17 \beta$-estradiol during $3 \mathrm{~h}$ at $37^{\circ} \mathrm{C}$.

\subsection{Flow cytometric analysis of PMN viability, apoptosis and necrosis}

Viability, apoptosis and necrosis of bovine PMN were quantified using a dual-color flow cytometric procedure as described by Van Oostveldt et al. [35]. Briefly, exposed phosphatidylserine was stained with fluorescein isothiocyanate (FITC) coupled Annexin V (Roche Diagnostics, Basel, Switzerland) and cellular nucleotides with propidium iodide (PI) (Sigma Chemicals Co.). Fluorescence was quantified using a FACScan flow cytometer (Becton Dickinson Immunocytometry Systems, San José, CA, USA). PMN were gated on dot plots representing cell size based on forward light scattering and granularity based on side light scattering. Viability, apoptosis and necrosis were determined by plotting log FL2 (PI) versus log FL1 (Annexin-VFITC). Quadrants were set on resulting plots, separating Annexin V-PI negative cells (viable cells) from Annexin V positive, PI negative cells (apoptotic cells) and Annexin VPI positive cells (necrotic cells). Data were corrected for autofluorescence which was defined as the fluorescence associated with non-labeled freshly isolated PMN.

\subsection{Analysis of $17 \beta$-estradiol and progesterone plasma levels}

Plasma was removed after the first centrifugation step of the PMN isolation procedure and was stored at $-20^{\circ} \mathrm{C}$. Plasma levels of $17 \beta$-estradiol and progesterone were determined using a radio-immunoassay technique according to Henry et al. [12]. Briefly, the plasma concentration of $17 \beta$-estradiol was measured after extraction with diethylether without further purification, using an antiserum against estradiol-3-hemisuccinate-
BSA raised in sheep. The plasma concentration of progesterone was measured after extraction with petroleum ether without further purification, using an antiserum against progesterone-11-hemisuccinate-BSA raised in sheep. The detection limit in bovine plasma for $17 \beta$-estradiol and progesterone was $20 \mathrm{pg} / \mathrm{mL}$ and $0.5 \mathrm{ng} / \mathrm{mL}$, respectively. The intra- and inter-assay coefficients of variation were 5.75 and $8.30 \%$ for $17 \beta$-estradiol and 7.05 and $8.75 \%$ for progesterone.

\subsection{Flow cytometric analysis of the CD47, CD11b and CD18 expression on the surface of bovine blood PMN}

The surface expression of CD47, CD11b and CD18 was determined using an indirect immunostaining protocol as described by Dosogne et al. [9] and Roets et al. [28]. Isolated PMN were suspended in RPMI 1640 with $1 \% \mathrm{BSA}$ and were incubated for 30 min at $37{ }^{\circ} \mathrm{C}$ with $100 \mu \mathrm{L}$ control solution (RPMI 1640 with $1 \%$ BSA) or $100 \mu \mathrm{L}$ of the primary antibody anti human CD47 (clone BRIC126, MCA911, Serotec, Oxford, UK), anti-bovine CD11b (clone CC126, MCA1425, Serotec) or anti-bovine CD18 (clone MF14B4, gift from J.J. Letesson) diluted in RPMI 1640 with 1\% BSA. After incubation, the cells were centrifuged $\left(200 \mathrm{~g}, 10 \mathrm{~min}, 4^{\circ} \mathrm{C}\right)$, washed and labeled with $100 \mu \mathrm{L}$ FITC-labeled secondary antibody (STAR9B, Serotec), diluted in a control solution, during $30 \mathrm{~min}$ in the dark on ice. The cells were centrifuged (200 $g$, $10 \mathrm{~min}, 4{ }^{\circ} \mathrm{C}$ ), washed, stabilized with $1 \%$ paraformaldehyde in PBS and kept at $4{ }^{\circ} \mathrm{C}$ in the dark until flow cytometric analysis. PMN were gated on dot plots representing cell size based on forward light scattering and granularity based on side light scattering. The gating of the PMN population was refined by defining the PMN population with the $\mathrm{CH} 138$ monoclonal antibody (VMRD Inc., Pullman, WA, USA), an IgM isotype antibody that specifically recognizes PMN. For this purpose, another aliquot of the cell suspension was labeled with the CH138 antibody as described for labeling 
of PMN with CD47, CD11b and CD18 antibodies. All data were corrected for autofluorescence as well as for non specific binding. In order to eliminate non specific binding, an isotype matched control (mouse $\mathrm{IgG}_{2}, \mathrm{MCA}$ 691, Serotec) and a negative control (only FITC labeling) were included. Gates were set to exclude $99 \%$ of the fluorescent cells in the negative and isotype matched control. Thus, positively stained cells were defined as those with staining intensity brighter than those exhibited by $99 \%$ of the isotype and negative controls.

Remaining PMN were used for the assessment of the CD47 expression by fluorescence microscopy. Nucleotides were additionally stained with $50 \mu \mathrm{L}$ PI during $20 \mathrm{~min}$ at $4{ }^{\circ} \mathrm{C}$ to visualize the nucleus and then washed three times with PBS (200 $g$ for 10 min at $4{ }^{\circ} \mathrm{C}$ ). Slides were prepared by cytocentrifugation ( $700 \mathrm{~g}$ for $5 \mathrm{~min}$, room temperature) and evaluated with a fluorescence microscope (Zeiss, Oberkochen, Germany).

\subsection{Preparation of the in vitro diapedesis model}

In vitro models were prepared as described previously [16]. Briefly, bovine mammary epithelial cells were isolated, purified and cultured as previously described by Smits et al. [31] and Cifrian et al. [6]. Membrane inserts $(12-\mathrm{mm}$ diameter, $3 \mu \mathrm{m}$ pore size, Millicell-PCF, Millipore Corp., Bedford, MA, USA) were coated with a commercial $0.1 \%$ calfskin collagen (type I) solution (Sigma Chemicals Co.) by adding $100 \mu \mathrm{L}$ of this solution to both sides of the inserts. The inserts were dried overnight at room temperature under a laminar air flow. Inverted collagen coated inserts were placed in sixwell tissue culture plates with both surfaces bathed in an $8 \mathrm{~mL}$ culture medium. The epithelial cell suspension containing $3 \times$ $10^{5}$ cells per $\mathrm{mL}$ was seeded on the the inserts and the inserts were kept in a $5 \%$ $\mathrm{CO}_{2}$ incubator at $37{ }^{\circ} \mathrm{C}$. The confluence of the epithelial cell layers was determined by measurement of transcellular electrical resistance (TER) using an Ohm meter (World
Precision Instruments, New Haven, CT, USA). Collagen coated inserts and collagen coated inserts with fibroblasts served as a control for TER measurements. TER values higher than the baseline values measured for models with fibroblasts or collagen were considered to be due to the confluence of the epithelial cell layer. Inserts with TER higher than $900 \Omega \times \mathrm{cm}^{2}$ were used in the experiment as values of $800 \Omega \times \mathrm{cm}^{2}$ and higher have previously been shown to give a good resistance against trypan blue diffusion during more than $180 \mathrm{~min}$. Differences in TER between inserts used for control, anti-CD18 and anti-CD47 were kept minimal within one cow (not higher than $147 \Omega \times \mathrm{cm}^{2}$ ) and between cows (not higher than $540 \Omega \times \mathrm{cm}^{2}$ ).

\subsection{Preparation of Zymosan activated serum}

Zymosan activated serum (ZAS) was used as a chemo-attractant and was prepared as described previously [16]. The concentration of C5a in ZAS solution was determined using an ELISA as described by Rainard et al. [27] and found to be $456 \mathrm{ng} / \mathrm{mL}$.

\subsection{PMN diapedesis assay}

The PMN diapedesis assay was performed as described previously [16]. PMN were pretreated with antibodies to human CD47 or bovine CD18 (positive control) [32] during $30 \mathrm{~min}$ at $37^{\circ} \mathrm{C}$ before being added to the upper chamber of the in vitro diapedesis model. Inserts were placed upright in 24-well plates. $2.5 \times 10^{6} \mathrm{PMN}$ were added on top of the inserts and stimulated to migrate across the membrane by the chemo-attractant ZAS, added in the lower well of the model. The 24-well plates were then placed into a $37^{\circ} \mathrm{C}$ incubator with $5 \%$ $\mathrm{CO}_{2}$. Collagen coated inserts, were removed after $2 \mathrm{~h}$ and the migrated PMN were counted in the lower well of the 24-well plates using a Coulter counter. Since PMN do not migrate as efficiently through models with epithelial cells, the duration of migration was increased with $30 \mathrm{~min}$. 


\subsection{Statistical analysis}

The effect of $17 \beta$-estradiol and progesterone on the viability, apoptosis and necrosis was evaluated by a mixed model with the cow as the random effect and the treatment, time and their interaction as categorical fixed effects. The same statistical analysis was used to evaluate the effect of $17 \beta$-estradiol and progesterone on TNF- $\alpha$ and gliotoxin induced apoptosis and necrosis. The influence of endogenous $17 \beta$-estradiol and progesterone levels was determined non parametrically by means of Spearman rank correlation coefficients. The influence of blocking antibodies for CD18 and CD47 on the number of migrated PMN was evaluated by a mixed model with the $\log _{10}$ of the number of migrated PMN as the response variable and cell layer and blocking antibody treatment as fixed effect factors. The two treatments were compared with the control using the Dunnett multiple comparisons technique at an overall significance level of $5 \%$. The influence of endogenous $17 \beta$-estradiol levels and $17 \beta$-estradiol treatment on the CD11b, CD18 and CD47 expression was evaluated by the Wilcoxon signed rank test, using the within cow difference between the two treatments (control and estradiol), because the normal distribution assumption did not hold.

\section{RESULTS}

\subsection{Influence of $17 \beta$-estradiol or progesterone on bovine blood PMN viability, apoptosis and necrosis}

The influence of endogenous $17 \beta$-estradiol and progesterone levels on viability, apoptosis and necrosis was first evaluated. Plasma concentrations of $17 \beta$-estradiol ranged from 8 to $53 \mathrm{pg} / \mathrm{mL}$ with a mean value of $31 \pm 4.5$ (SEM). Plasma concentrations of progesterone ranged from 1.00 to $2.15 \mathrm{ng} / \mathrm{mL}$ with a mean value of $1.50 \pm$ 0.14 . Viability, apoptosis and necrosis were not correlated with the endogenous
$17 \beta$-estradiol and progesterone levels $(P>$ $0.05)(n=11)$.

Bovine blood PMN were then incubated with different concentrations of $17 \beta$-estradiol and progesterone during $24 \mathrm{~h}$. At 1, 3, 6 and $24 \mathrm{~h}$, viability, apoptosis and necrosis were assessed. Incubation with $17 \beta$-estradiol or progesterone did not affect viability, apoptosis or necrosis $(P>0.05)(n=5)$ (Tab. I). Viability, apoptosis and necrosis of bovine PMN changed only over time $(P<$ $0.0001)$. The non viable PMN population consisted mainly of apoptotic cells in all treatments. Within the first $6 \mathrm{~h}$, the percentage necrotic cells did not exceed $3.4 \%$ whereas the overall percentage apoptotic cells was $3.05,6.14$ and $14.78 \%$ after 1,3 and $6 \mathrm{~h}$ of incubation, respectively. After $24 \mathrm{~h}$ the mean value of percentage apoptotic cells $(43.16 \%)$ was still extensively higher than that of percentage necrotic cells $(14.13 \%)$.

Subsequently, bovine blood PMN were incubated with $17 \beta$-estradiol or progesterone and a combination of TNF- $\alpha$ and gliotoxin. After 1, 3 and $5 \mathrm{~h}$ of incubation, viability, apoptosis and necrosis were assessed. Viability, apoptosis and necrosis were significantly influenced by the addition of TNF- $\alpha$ and gliotoxin $(P<0.05)(n=6)$. In addition, progesterone induced an overall significantly increased viability $(P<0.05)$ by significantly delaying apoptosis induced by TNF- $\alpha$ and gliotoxin $(P<0.05)(n=6)$. This effect was not observed for TNF- $\alpha$ and gliotoxin induced necrosis. 17 $\beta$-Estradiol had no influence on either induced apoptosis nor necrosis (Fig. 1) $(P>0.05)(n=6)$.

\subsection{Expression of CD47 on the surface of bovine blood PMN and importance of CD47 for the migration of bovine PMN}

\subsubsection{Expression of $C D 47$ on the surface of bovine blood PMN}

The expression of CD47 on the surface of bovine blood PMN was assessed by flow 
Table I. Influence of different concentrations of $17 \beta$-estradiol and progesterone on the viability (\%), apoptosis (\%) and necrosis (\%) of bovine polymorphonuclear neutrophil leukocytes. Data are means \pm SEM.

\begin{tabular}{|c|c|c|c|c|}
\hline \multirow{2}{*}{$\begin{array}{l}\text { Concentration } \\
(\mathrm{ng} / \mathrm{mL})\end{array}$} & \multicolumn{4}{|c|}{ Time of incubation (h) } \\
\hline & 1 & 3 & 6 & 24 \\
\hline & \multicolumn{4}{|c|}{ Viability (\%) } \\
\hline \multicolumn{5}{|l|}{ Estradiol } \\
\hline 0 & $95.69 \pm 2.14$ & $94.88 \pm 3.08$ & $85.49 \pm 5.20$ & $55.44 \pm 7.87$ \\
\hline 0.01 & $95.91 \pm 1.54$ & $90.28 \pm 2.03$ & $80.40 \pm 3.45$ & $46.69 \pm 19.12$ \\
\hline 1 & $95.21 \pm 2.99$ & $92.71 \pm 3.57$ & $81.41 \pm 8.55$ & $38.00 \pm 7.60$ \\
\hline 10 & $97.10 \pm 0.10$ & $93.20 \pm 3.11$ & $83.03 \pm 6.15$ & $37.06 \pm 7.46$ \\
\hline \multicolumn{5}{|l|}{ Progesterone } \\
\hline 0 & $95.69 \pm 2.14$ & $94.88 \pm 3.08$ & $85.49 \pm 5.20$ & $55.44 \pm 7.87$ \\
\hline 5 & $97.11 \pm 2.16$ & $93.48 \pm 6.76$ & $76.22 \pm 27.75$ & $22.32 \pm 5.36$ \\
\hline 50 & $96.29 \pm 3.81$ & $89.99 \pm 10.42$ & $76.42 \pm 18.57$ & $29.42 \pm 7.60$ \\
\hline 500 & $96.22 \pm 3.84$ & $91.04 \pm 7.08$ & $78.46 \pm 18.20$ & $44.94 \pm 10.19$ \\
\hline & \multicolumn{4}{|c|}{ Apoptosis $(\%)$} \\
\hline \multicolumn{5}{|l|}{ Estradiol } \\
\hline 0 & $3.64 \pm 2.09$ & $4.19 \pm 3.03$ & $11.94 \pm 5.07$ & $35.34 \pm 9.60$ \\
\hline 0.01 & $3.32 \pm 1.64$ & $5.91 \pm 2.65$ & $13.54 \pm 4.86$ & $40.16 \pm 15.66$ \\
\hline 1 & $3.09 \pm 1.75$ & $5.77 \pm 3.49$ & $15.00 \pm 8.27$ & $52.03 \pm 11.77$ \\
\hline 10 & $2.48 \pm 1.04$ & $5.60 \pm 3.22$ & $15.16 \pm 6.16$ & $42.80 \pm 9.42$ \\
\hline \multicolumn{5}{|l|}{ Progesterone } \\
\hline 0 & $3.64 \pm 2.09$ & $4.19 \pm 3.03$ & $11.94 \pm 5.07$ & $35.34 \pm 9.60$ \\
\hline 5 & $2.50 \pm 1.03$ & $5.52 \pm 3.08$ & $9.93 \pm 4.59$ & $46.01 \pm 15.92$ \\
\hline 50 & $3.10 \pm 1.74$ & $8.82 \pm 4.64$ & $20.04 \pm 8.40$ & $52.80 \pm 14.50$ \\
\hline 500 & $3.22 \pm 1.63$ & $7.14 \pm 3.42$ & $17.88 \pm 8.79$ & $40.60 \pm 10.68$ \\
\hline & \multicolumn{4}{|c|}{ Necrosis (\%) } \\
\hline \multicolumn{5}{|l|}{ Estradiol } \\
\hline 0 & $0.57 \pm 0.11$ & $0.50 \pm 0.20$ & $2.02 \pm 0.80$ & $8.27 \pm 1.81$ \\
\hline 0.1 & $0.60 \pm 0.20$ & $1.57 \pm 0.55$ & $3.40 \pm 1.47$ & $20.15 \pm 13.57$ \\
\hline 1 & $0.44 \pm 0.07$ & $1.09 \pm 0.40$ & $2.79 \pm 1.31$ & $8.49 \pm 3.53$ \\
\hline 10 & $0.37 \pm 0.07$ & $0.75 \pm 0.21$ & $1.56 \pm 0.48$ & $16.12 \pm 4.46$ \\
\hline \multicolumn{5}{|l|}{ Progesterone } \\
\hline - & $0.57 \pm 0.11$ & $0.50 \pm 0.20$ & $2.02 \pm 0.80$ & $8.27 \pm 1.81$ \\
\hline 5 & $0.31 \pm 0.06$ & $0.73 \pm 0.12$ & $1.39 \pm 0.43$ & $25.51 \pm 7.12$ \\
\hline 50 & $0.48 \pm 0.83$ & $0.91 \pm 0.20$ & $2.41 \pm 0.89$ & $14.98 \pm 5.12$ \\
\hline 500 & $0.44 \pm 0.10$ & $1.13 \pm 0.39$ & $2.28 \pm 0.10$ & $11.27 \pm 3.99$ \\
\hline
\end{tabular}

cytometry. A clear expression of CD47 was observed (Fig. 2A). The mean fluorescence intensity (MFI) for CD47 was $64 \pm 12$ (SEM) $(n=7)$ after subtraction of fluorescence associated with the autofluorescence, isotype matched control and secondary antibody control. The mean MFI values for
CD11b and CD18 (positive controls) were $104 \pm 12$ and $102 \pm 8(n=7)$, respectively.

The CD47 surface expression was confirmed by fluorescence microscopy. FITC and PI staining were used to visualize the CD47 expression and multilobulated morphology, typical for the PMN nucleus, 

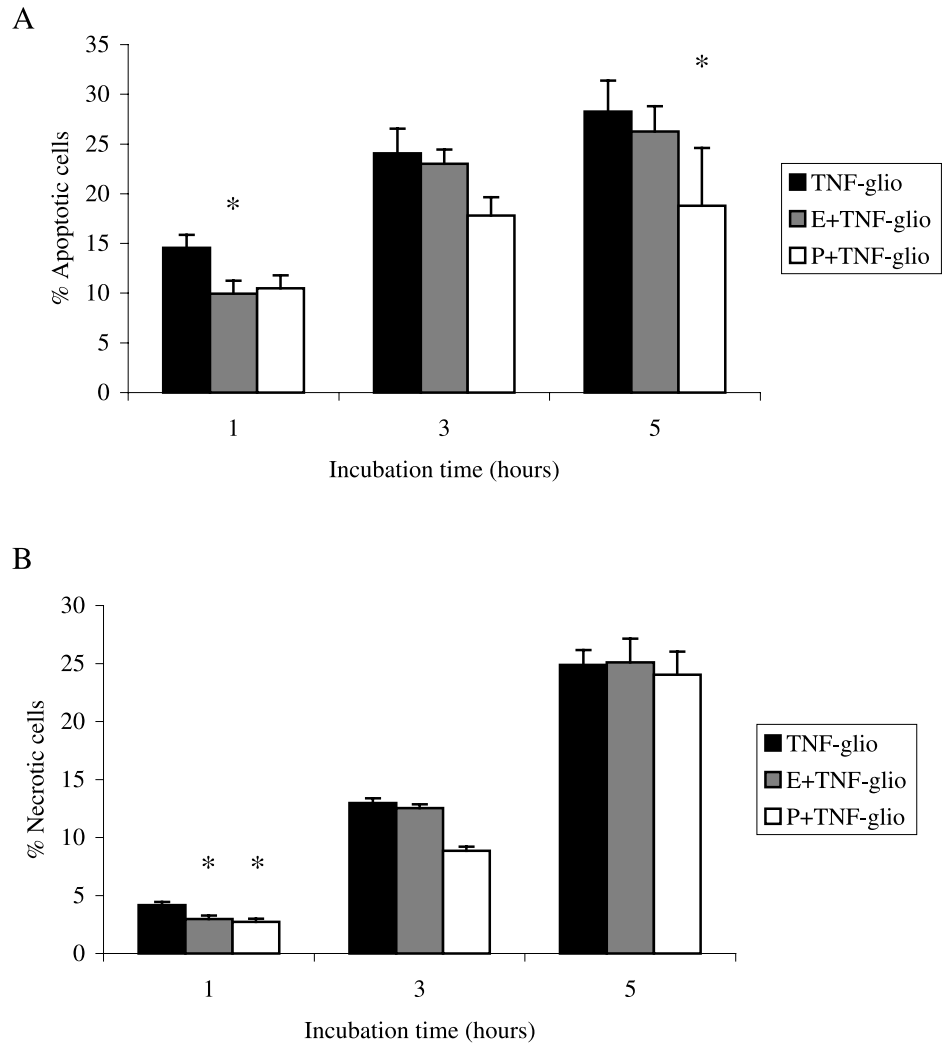

Figure 1. Influence of $17 \beta$-estradiol (E) and progesterone $(\mathrm{P})$ on TNF- $\alpha$ and gliotoxin induced apoptosis and necrosis. * Denotes a significant difference at $5 \%$ global significance level.

respectively. CD47 was present in clusters on the cell surface of PMN (Fig. 2B). Background staining for FITC was minimal in the isotype matched control and secondary antibody control samples.

\subsubsection{Importance of CD47 for migration of bovine PMN}

The importance of CD47 expression for migration of bovine PMN was determined in an in vitro model which consisted of collagen coated inserts with or without bovine mammary epithelial cells. Migration of PMN through collagen was significantly reduced after incubation with anti-CD47 $(P<0.05)$ or anti-CD18 antibodies (positive control) $(P<0.05)(n=7)$. Addition of anti-CD47 or anti-CD18 antibodies resulted in a $38 \%$ $\pm 24(\mathrm{SEM})$ and $78 \% \pm 11$ reduction of PMN migration, respectively. Migration of PMN through collagen with an epithelial cell layer was not significantly reduced after the addition of anti-CD47 or antiCD18 antibodies $(P>0.05)(n=7)$.

\subsection{Influence of $17 \beta$-estradiol on CD11b, CD18 and CD47 expression on bovine blood PMN}

The influence of endogenous $17 \beta$-estradiol and progesterone levels on the CD11b, CD18 and CD47 expression was first evaluated. Plasma concentrations of $17 \beta$-estradiol ranged from 17 to $136 \mathrm{pg} / \mathrm{mL}$ with a mean value of $49 \pm 17$ (SEM). Plasma 


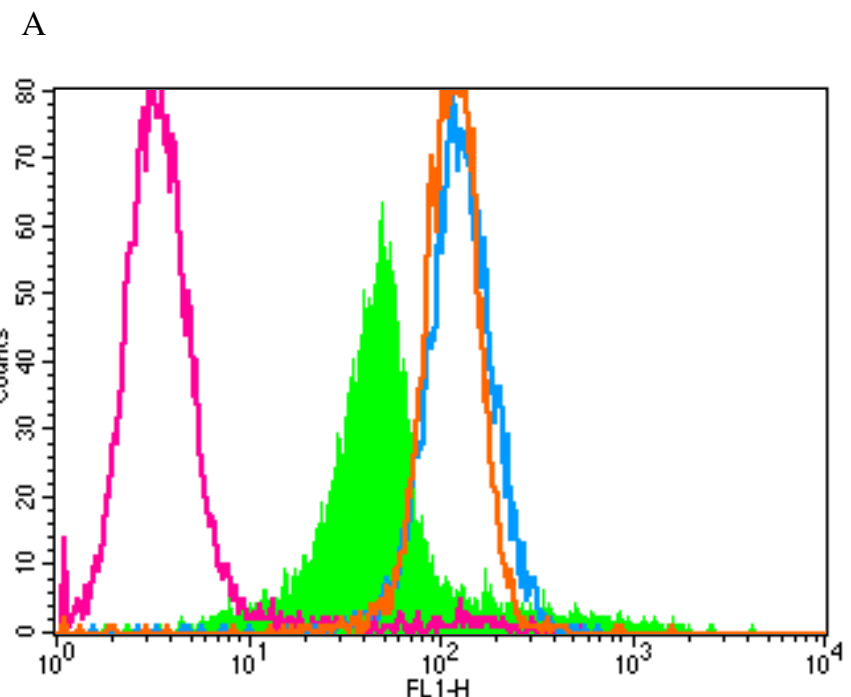

B

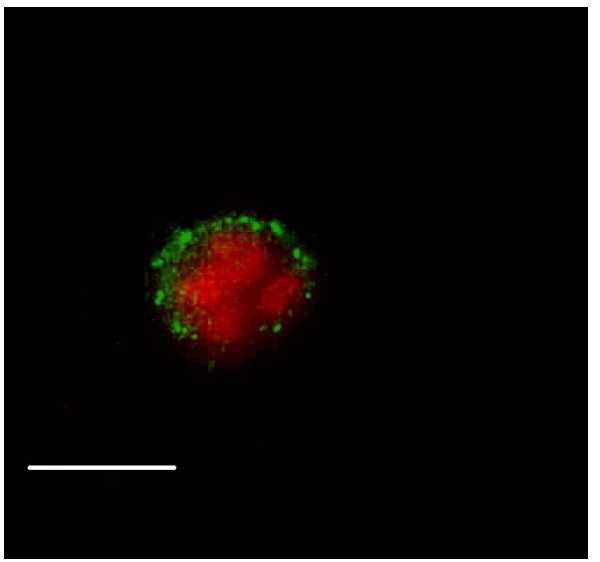

Figure 2. (A) Flow cytometrical detection of CD47 expression on bovine PMN compared with the CD11b and CD18 expression; green: CD47, pink: isotype matched control, blue: $\mathrm{CD} 11 \mathrm{~b}$ and orange: CD18. (B) Fluorescence microscopical detection of FITC labeled CD47 (green) on the surface of bovine PMN. The polymorphic shape of the nucleus (red) identifies the cell as PMN. The bar represents $15 \mu \mathrm{m}$. A color version of this figure is available at www.edpsciences.org.

progesterone concentrations ranged from 0.75 to $1.45 \mathrm{ng} / \mathrm{mL}$ with a mean value of $1.24 \pm 0.09$. No significant influence of endogenous $17 \beta$-estradiol or progesterone levels on the expression of CD11b, CD18 or CD47 of bovine blood PMN was found $(P>0.05)(n=7)$.

Bovine blood PMN were then incubated with $17 \beta$-estradiol during $3 \mathrm{~h}$ and the influence of $17 \beta$-estradiol treatment on CD11b, CD18 and CD47 expression was evaluated.

$17 \beta$-Estradiol had no significant influence on the expression of CD11b or CD18 $(P>$ $0.05)(n=7)$. In contrast, the expression of CD47 decreased significantly after $17 \beta-$ estradiol treatment $(P<0.05)(n=7)$. In Figure 3 , the individual MFI values for CD11b, CD18 and CD47 expression are shown for untreated and estradiol treated samples. The median of the paired difference in MFI values was -1.55 for CD $11 b$, -4.45 for CD18 and 5.96 for CD47. 


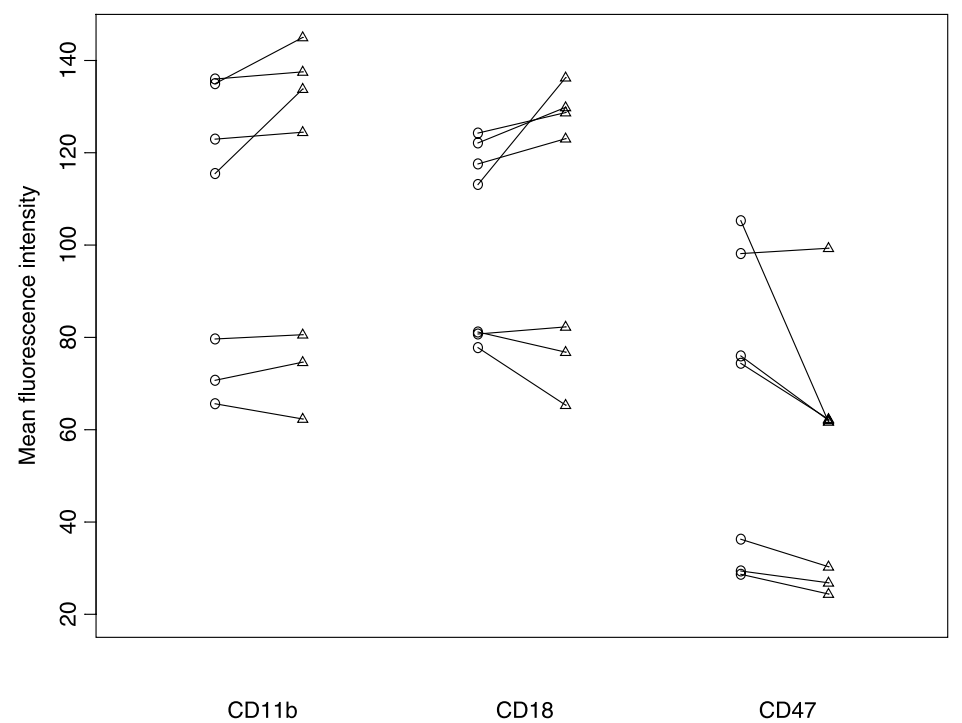

Figure 3. Influence of $17 \beta$-estradiol on the CD11b, CD18 and CD47 expression. The individual MFI values for CD11b, CD18 and CD47 expression are shown for untreated $(\mathrm{O})$ and estradiol $(\Delta)$ treated samples. The lines connect MFI values corresponding to untreated and $17 \beta$-estradiol treated samples of the same cow.

\section{DISCUSSION}

In a first analysis the effect of $17 \beta$-estradiol and progesterone on PMN viability, apoptosis and necrosis was evaluated. There was no correlation between the viability, apoptosis or necrosis and the endogenous $17 \beta$-estradiol or progesterone levels at the time of sampling. In analogy, in vitro treatment with $17 \beta$-estradiol or progesterone did not result in a significant direct effect of these sex steroids after 1, 3, 6 or $24 \mathrm{~h}$ of incubation for any of the concentrations used. Apoptosis increased with time at the same rate for all treatments, whereas the increase of necrosis was limited. Since PMN were isolated from cows in the last month of gestation, no effect of $17 \beta$-estradiol and progesterone might have been observed due to the fact that blood PMN are exposed to high progesterone and relatively high $17 \beta$ estradiol levels at the end of pregnancy.

The literature on the direct influence of $17 \beta$-estradiol and progesterone on the viability of blood PMN is restricted to apopto- sis of human PMN and reveals conflicting results. Cox [7] and Liles et al. [17] report that progesterone has no influence on the apoptosis of blood PMN, whereas Molloy et al. [22] describe that physiological doses of $17 \beta$-estradiol and progesterone cause a delay in PMN apoptosis. In the latter study the combination of $17 \beta$-estradiol and progesterone was additionally evaluated for its influence on viability, apoptosis and necrosis. Despite their individual influence, no synergistic or antagonistic effect was observed for these sex steroids [22].

Since no significant effect of $17 \beta$-estradiol and progesterone was observed on spontaneous apoptosis, the effect of both sex steroids on induced apoptosis was subsequently evaluated. Incubation of bovine blood PMN with TNF- $\alpha$ in combination with gliotoxin was used to induce apoptosis. TNF- $\alpha$ is one of the most important orchestrators of inflammation. However, when evaluating the effect of this cytokine on the lifespan of PMN one should be aware that it can exert either anti- or pro-apoptotic 
effects depending on the concentration, time of exposure and cell type [24, 34, 38]. The evaluation of the effect of pro-apoptotic doses of TNF- $\alpha$ on the lifespan of bovine PMN resulted in a slight, albeit non significant stimulation of apoptosis [25]. Gliotoxin, a potent and specific inhibitor of $\mathrm{NF}-\kappa \mathrm{B}$, has previously been shown to sensitize cells to the pro-apoptotic effects of TNF- $\alpha$ [38]. In analogy, Notebaert et al. [25] observed an extensive increase in the rate of bovine PMN apoptosis after incubation with TNF- $\alpha$ and gliotoxin. We observed a significant decrease in viability associated with a significant increase in apoptosis and necrosis after incubation with TNF- $\alpha$ and gliotoxin which was in agreement with the study of Notebaert et al.

The co-incubation of bovine blood PMN with $17 \beta$-estradiol or progesterone and a combination of TNF- $\alpha$ and gliotoxin, resulted in a significant survival effect of progesterone. These results were in agreement with the study of Vegeto et al. [36] and Gandolfi et al. [10] where TNF- $\alpha$-induced apoptosis in monoblastoid cells and anterior pituitary cells was delayed by progesterone. However, Vegeto et al. also report a survival effect for $17 \beta$-estradiol, which was not found in our study nor in the study of Gandolfi et al. [10]. The latter authors found a synergistic effect for $17 \beta$-estradiol on TNF- $\alpha$-induced apoptosis [10]. As it has been described that effects of steroid hormones are highly dependent on the cell type and cell differentiation state, these differences may be responsible for the noticed dissimilarities $[20,22,36]$. To the best of our knowledge, the influence of $17 \beta$-estradiol or progesterone on TNF- $\alpha$ induced apoptosis has not yet been described for bovine blood PMN. One study assesses the influence on Fas-induced apoptosis of human PMN and reports that $17 \beta$-estradiol nor progesterone affect Fas-induced apoptosis [22].

We and other authors previously observed that $17 \beta$-estradiol decreases migration of PMN of bovine and human origin $[14,16$,
21]. In order to gain insight into the molecular mechanism by which $17 \beta$-estradiol affects PMN migration, the influence of $17 \beta$-estradiol on the expression of molecules important in PMN migration [18, 26, 32], was evaluated. The participation of the $\beta_{2}$-integrin subunits CD11b and CD18 in the migratory process is well established for human as well as for bovine PMN (reviewed in $[32,39])$. The presence and functional role of CD47 is much less documented than that of CD11b and CD18, and not yet reported for bovine PMN. Nevertheless, it has been shown that CD47 facilitates the migration of human PMN. Therefore, in a second experiment we analyzed whether CD47 is expressed on bovine PMN and whether it contributes to their migration.

The presence of CD47 on the cell surface could be confirmed by flow cytometry and fluorescence microscopy. Moreover, migration of bovine PMN through collagen coated inserts was significantly reduced after incubation with anti-CD47 antibody, for which an inhibiting activity has been shown by Seiffert et al. [30]. In analogy, anti-CD18 clearly blocked migration through collagen. The inhibition by anti-CD18 was, however, more clearly pronounced than the inhibition by anti-CD47. Nevertheless, it needs to be remarked that experiments using antibodies to assess the importance of cell surface molecules for migration, are only suggestive and do not prove the functional role of these molecules since antibodies may inhibit migration by non specific binding to PMN. Nevertheless, our suggestion about a role for CD47 in the migration of bovine PMN is further strengthened by data provided in the literature for human PMN. Liu et al. [18] describe that CD47 regulates the rate of migration of human PMN. In our study, migration through bovine mammary epithelial cells was also considered, but in this case the blocking effect of CD47- and CD18-antibodies was not significant. Since PMN diapedesis through epithelial cells was already highly reduced compared to migration through collagen, it is suggested that it was probably not possible to measure 
an additional reduction of migration by anti-CD47 or -CD18 antibodies. Moreover, a high variability was observed among the individual cows, which may further explain the absence of a significant reduction. We can, however, exclude that the variability for PMN diapedesis through epithelial cells was due to differences in TER of the inserts since these were kept minimal both within one cow and between cows. We also considered the possibility of increasing the migration through epithelial cells by prolonging the diapedesis time. However, the total diapedesis time was intentionally limited to $2 \mathrm{~h}$ and $30 \mathrm{~min}$ since Liu et al. [18] describe that blocking of cell surface CD47 with inhibitory antibodies does not halt but merely delays PMN migration. By further increasing the migration time, the total number of migrated PMN under CD47 blocking conditions will eventually equal that of the control. Concerning CD18, it has been described by Smits et al. [32] that antiCD18 antibodies, compared with anti-CD11b antibodies, only partly block bovine PMN migration through bovine mammary epithelial cells.

In a final experiment we evaluated the role of CD11b, CD18 and CD47 in the underlying mechanism of a $17 \beta$-estradiol induced depression of migration of bovine PMN, by monitoring the effect of $17 \beta$-estradiol on their expression. No influence of endogenous $17 \beta$-estradiol levels was found on the CD11b, CD18 and CD47 expression. The CD11b and CD18 expression was also not influenced by $17 \beta$-estradiol treatment. We therefore suggest that $17 \beta$-estradiol levels does not influence migration by direct alteration of the $\mathrm{CD} 11 \mathrm{~b}$ or $\mathrm{CD} 18$ expression. In contrast, even though endogenous $17 \beta$-estradiol did not correlate with the CD47 expression, a significant decrease of the CD47 expression was observed after in vitro $17 \beta$-estradiol treatment. Since it is suggested that CD47 affects the rate of PMN migration, this decrease can partly explain the negative influence of $17 \beta$-estradiol on the migration of bovine PMN. A comparison of the differences in endog- enous $17 \beta$-estradiol levels observed in the plasma of cows in the last month of gestation with those applied in the in vitro assay may explain why only an in vitro effect of $17 \beta$-estradiol on the CD47 expression was found. For the endogenous levels, the difference between the lowest and highest $17 \beta$-estradiol level was limited (i.e. 119 pg/ $\mathrm{mL}$ ), while the difference between the control and 17 $\beta$-estradiol treatment was an order of magnitude higher (i.e. $1000 \mathrm{pg} / \mathrm{mL}$ ). We therefore suggest that changes in $17 \beta$-estradiol levels need to be sufficiently pronounced, as is the case in the periparturient period, in order to induce changes in CD47 expression.

Although CD11b and CD18 expression on PMN has been well studied and their importance for PMN migration is commonly accepted, the literature concerning the influence of sex steroids on their expression is only scarce. Molloy et al. describe the influence of $17 \beta$-estradiol treatment on the $\mathrm{CD} 11 \mathrm{~b}$ expression and in agreement with our results, the expression of CD11b on human PMN was not altered by $17 \beta$-estradiol treatment [22]. In contrast to our results, the CD18 expression was found to be reduced by $17 \beta$-estradiol after a 6 - $\mathrm{h}$ incubation in the study of Garcia-Duran et al. [11]. Apart from the species differences, the use of a higher concentration of $17 \beta$-estradiol during a longer time period may explain the different outcome of our study and the study of Gandolfi et al. [10]. To the best of our knowledge, no literature is available concerning the influence of sex steroids on CD47 expression.

From this study, it can be concluded that $17 \beta$-estradiol and progesterone do not affect spontaneous apoptosis of bovine blood PMN isolated from cows in the last month of gestation. In contrast, a survival effect was observed for progesterone, but not for $17 \beta$-estradiol, on TNF- $\alpha$ and gliotoxin induced apoptosis. Subsequently it was shown that CD47 is expressed on the surface of bovine blood PMN and it is suggested that CD47 is involved in the migration of bovine 
PMN through collagen. Finally, a 17 $\beta$-estradiol induced decrease of the expression of CD47, but not of the expression of the $\beta_{2}$-integrin subunits CD11b or CD18, was observed. The results from this study extend the previous demonstrations of the suppressive effect of $17 \beta$-estradiol on PMN migration from cows in their last month of gestation and indicate that the altered expression of CD47 may contribute to this phenomenon. However, further research is needed to unequivocally clarify the role of CD47 in PMN diapedesis.

\section{ACKNOWLEDGEMENTS}

This study was supported by the Bijzonder Onderzoeksfonds of Ghent University (BOF, grant No. 01111401 to I. Lamote), by the Flemish Institute for the Encouragement of Research in the Industry (IWT, grant No. 030784 to A. De Ketelaere) and by the National Fund for Scientific Research (FWO, grant No. 3G008699). The authors wish to thank J.J. Lettesson (Facultés Universitaires Notre Dame de la Paix, Namur, Belgique) for the anti-CD18 antibody, P. Rainard (INRA, Nouzilly, France) for the determination of the C5a concentration, M. Corijn for the determination of the steroid hormone plasma levels and K. Demeyere and E. Vander Elstraeten for their excellent technical assistance.

\section{REFERENCES}

[1] Akers M., Lactation and the mammary gland, 1st edition, Iowa State Press, Iowa, 2002.

[2] Bell A., Regulation of organic nutrient metabolism during transition from late pregnancy to early lactation, J. Anim. Sci. 73 (1995) 28042819.

[3] Burton J., Erskine R., Immunity and mastitis. Some new ideas for an old disease, Vet. Clin. North Am. Food Anim. Pract. 19 (2003) 1-45.

[4] Burvenich C., Van Merris V., Mehrzad J., Diez-Fraile A., Duchateau L., Severity of E. coli mastitis is mainly determined by cow factors, Vet. Res. 34 (2003) 521-564.

[5] Chang L., Madsen S., Toelboell T., Weber P., Burton J., Effects of glucocorticoids on Fas gene expression in bovine blood neutrophils, J. Endocrinol. 183 (2004) 569-583.
[6] Cifrian E., Guidry A., O'Brien C., Keys J., Marquardt W., Bovine mammary teat and ductal epithelial cell cultures, Am. J. Vet. Res. 55 (1994) 239-246.

[7] Cox G., Glucocorticoid treatment inhibits apoptosis in human neutrophils. Separation of survival and activation outcomes, J. Immunol. 154 (1995) 4719-4725.

[8] Diez-Fraile A., Meyer E., Burvenich C., Sympathoadrenal and immune system activation during the periparturient period and their association with bovine coliform mastitis, Vet. Q. 25 (2003) 31-44.

[9] Dosogne H., Burvenich C., van Werven T., Roets E., Noordhuizen-Stassen E., Goddeeris B., Increased surface expression of CD11b receptors on polymorphonuclear leukocytes is not sufficient to sustain phagocytosis during Escherichia coli mastitis in early postpartum dairy cows, Vet. Immunol. Immunopathol. 60 (1997) 47-59.

[10] Gandolfi M., Jaita G., Zaldivar V., Zarate S., Ferrari L., Pisera D., Castro M., Seilicovich A., Progesterone antagonizes the permissive action of estradiol on tumor necrosis factoralfa-induced apoptosis of anterior pituitary cells, Endocrinology 146 (2005) 736-743.

[11] Garcia-Duran M., de Frutos T., Diaz-Recasens J., Garcia-Galvez G., Jimenez A., Monton M., Farré J., Sanchez de Miguel L., GonzalezFernandez F., del Mar Arriero M., Rico L., Garcia R., Casado S., Lopez-Farré A., Estrogen stimulates neuronal nitric oxide synthase protein expression in human neutrophils, Circ. Res. 85 (1999) 1020-1026.

[12] Henry M., Figueiredo A., Palhares M., Corijn M., Clinical and endocrine aspects of the oestrus cycle in donkeys, J. Reprod. Fertil. 35 (1987) 297-303.

[13] Hoedemaker M., Lund L., Wagner W., Influence of arachidonic acid metabolites and steroids on function of bovine polymorphonuclear neutrophils, Am. J. Vet. Res. 53 (1992) 1534-1539.

[14] Ito I., Hayashi T., Yamada K., Kuzuya M., Naito M., Iguchi A., Physiological concentrations of estradiol inhibits polymorphonuclear leukocyte chemotaxis via a receptor mediated system, Life Sci. 56 (1995) 2247-2253.

[15] Kehrli M., Harp J., Immunity in the mammary gland, Vet. Clin. North Am. Food Anim. Pract. 17 (2001) 495-516.

[16] Lamote I., Meyer E., Duchateau L., Burvenich C., Influence of 17beta-estradiol, progesterone, and dexamethasone on diapedesis and viability of bovine blood polymorphonuclear leukocytes, J. Dairy Sci. 87 (2004) 33403349. 
[17] Liles W., Dale D., Klebanoff S., Glucocorticoids inhibit apoptosis of human neutrophils, Blood 86 (1995) 3181-3188.

[18] Liu Y., Merlin D., Burst S., Pochet M., Madara J., Parkos C., The role of CD47 in neutrophil transmigration. Increased rate of migration correlates with increased cell surface expression of CD47, J. Biol. Chem. 276 (2001) 40156-40166.

[19] Madsen S., Chang A., Hickey M., Rosa G., Coussens P., Burton J., Microarray analysis of gene expression in blood neutrophils of parturient cows, Physiol. Genomics 16 (2004) 212-221.

[20] Meagher L., Cousin J., Seckl J., Haslett C., Opposing effects of glucocorticoids on the rate of apoptosis in neutrophilic and eosinophilic granulocytes, J. Immunol. 156 (1996) 4422-4428.

[21] Miyagi M., Aoyama H., Morishita M., Iwamoto Y., Effects of sex hormones on chemotaxis of human peripheral polymorphonuclear leukocytes and monocytes, J. Periodontol. 63 (1992) 28-32.

[22] Molloy E., O'Neill A, Grantham J, SheridanPereira M., Fitzpatrick J., Webb D., Watson R., Sex-specific alterations in neutrophil apoptosis: the role of estradiol and progesterone, Blood 102 (2003) 2653-2659.

[23] Moreira da Silva F., Burvenich C., MassartLeën A.M., Brossé L., Assessment of blood neutrophil oxidative burst activity in dairy cows during the period of parturition, Anim. Sci. 67 (1998) 421-426.

[24] Murray J., Barbara J., Dunkley S., Lopez A., VanOstade X., Condliffe A., Dransfield I., Haslett C., Chilvers E., Regulation of neutrophil apoptosis by tumor necrosis factoralpha: requirement for TNFR55 and TNFR75 for induction of apoptosis in vitro, Blood 90 (1997) 2772-2783.

[25] Notebaert S., Duchateau L., Meyer E., NFkappaB inhibition accelerates apoptosis of bovine neutrophils, Vet. Res. 36 (2005) 229240.

[26] Parkos C., Cell adhesion and migration I. Neutrophil adhesive interactions with intestinal epithelium, Am. J. Physiol. (1997) G763G768.

[27] Rainard P., Sarradin P., Poutrel B., Quantification of $\mathrm{C} 5 \mathrm{a} / \mathrm{C} 5 \mathrm{a}$ (desArg) in bovine plasma, serum and milk, Vet. Res. 29 (1998) 73-88.

[28] Roets E., Burvenich C., Diez-Fraile A., Noordhuizen-Stassen E., Evaluation of the role of endotoxin and cortisol on modulation of CD18 adhesion receptors in cows with mastitis caused by Escherichia coli, Am. J. Vet. Res. 60 (1999) 2-9.
[29] Roth J., Kaeberle M., Hsu W., Effect of estradiol and progesterone on lymphocyte and neutrophil functions in steers, Infect. Immun. 35 (1982) 997-1002.

[30] Seiffert M., Cant C., Chen Z., Rappold I., Brugger W., Kanz L., Brown E., Ullrich A., Human signal-regulatory protein is expressed on normal, but not on subsets of leukemic myeloid cells and mediates cellular adhesion involving its counterreceptor CD47, Blood (1999) 3633-3643.

[31] Smits E., Cifrian E., Guidry A., Rainard P., Burvenich C., Paape M., Cell culture system for studying bovine neutrophil diapedesis, J. Dairy Sci. 79 (1996) 1353-1360.

[32] Smits E., Burvenich C., Guidry A., MassartLeen A., Adhesion receptor CD11b/CD18 contributes to neutrophil diapedesis across the bovine blood-milk barrier, Vet. Immunol. Immunopathol. 73 (2000) 255-265.

[33] Subandrio A., Sheldon I., Noakes D., Peripheral and intrauterine neutrophil function in the cow: the influence of endogenous and exogenous sex steroid hormones, Theriogenology 53 (2000) 1591-1608.

[34] van den Berg J., Weyer S., Weening J., Roos D., Kuijpers T., Divergent effects of tumor necrosis factor alpha on apoptosis of human neutrophils, J. Leukoc. Biol. 69 (2001) 467473.

[35] Van Oostveldt K., Dosogne H., Burvenich C., Paape M., Brochez V., Van den Eeckhaut E., Flow cytometric procedure to detect apoptosis of bovine polymorphonuclear leukocytes in whole blood, Vet. Immunol. Immunopathol. 70 (1999) 125-133.

[36] Vegeto E., Pollio G., Pellicciari C., Maggi A., Estrogen and progesterone induction of survival of monoblastoid cells undergoing TNFalfa-induced apoptosis, FASEB J. 13 (1999) 793-803.

[37] von Dadelszen P., Watson R., Noorwali F., Marshall J., Parodo J., Farine D., Lye S., Ritchie J., Rotstein O., Maternal neutrophil apoptosis in normal pregnancy, preeclampsia, and normotensive intrauterine growth restriction, Am. J. Obstet. Gynecol. 181 (1999) 408414.

[38] Walmsley S., Cowburn A., Sobolewski A., Murray J., Farahi N., Sabroe I., Chilvers E., Characterization of the survival effect of tumour necrosis factor-alfa in human neutrophils, Biochem. Soc. Trans. 32 (2004) 456460.

[39] Zen K., Parkos C., Leukocyte-epithelial interactions, Curr. Opin. Cell Biol. 15 (2003) 557567. 